\title{
Kernos
}

Revue internationale et pluridisciplinaire de religion grecque antique

12 | 1999

Varia

\section{G. FREYBURGER, L. PERNOT (éds), Du héros païen au saint chrétien}

\section{André Motte}

\section{OpenEdition}

\section{Journals}

Édition électronique

URL : http://journals.openedition.org/kernos/743

DOI : $10.4000 /$ kernos.743

ISSN : 2034-7871

\section{Éditeur}

Centre international d'étude de la religion grecque antique

Édition imprimée

Date de publication : 1 janvier 1999

Pagination : 318

ISSN : 0776-3824

Référence électronique

André Motte, «G. Freyburger, L. Pernot (éds), Du héros païen au saint chrétien », Kernos [En ligne], 12 | 1999, mis en ligne le 13 avril 2011, consulté le 11 mars 2021. URL : http://journals.openedition.org/ kernos/743 ; DOI : https://doi.org/10.4000/kernos.743 
plus vaste, par exemple les livres de R.L. Wilken, The Christians as the Romans saw Them (New Haven-London, 1984) et de N. Zeegers-Vander Vorst, Les citations des poètes grecs chez les apologistes chrétiens du II siècle (Louvain, 1972).

Dans une prochaine édition du volume, on pourra facilement corriger les coquilles qui gênent la lecture (par exemple Rufin d'Alexandrie au lieu de Rufin d'Aquilée à la page 281 !). Malheureusement, même l'auteur de ce compte rendu a été victime d'une faute typographique regrettable à la page 208 , note 17 : P. Franeo, au lieu de Pier Franco Beatrice! Mais cela, évidemment, n'enlève rien à la valeur du livre qui trouve sa place à juste titre parmi les meilleurs travaux publiés au cours de cette décennie sur l'histoire sociale et religieuse de l'Antiquité Tardive.

Pier Franco Beatrice (Università di Padova)

Gérard Freyburger et Laurent Pernot (éds), Du béros païen au saint chrétien. Actes du colloque organisé par le Centre d'Analyse des Rhétoriques Religieuses de l'Antiquité (C.A.R.R.A.), Strasbourg, 1-2 décembre 1995, Paris, Institut d'Études Augustiniennes, 1997. 1 vol. $16 \times 24,5 \mathrm{~cm}, 231$ p. (Série Antiquité, 154). ISBN : 2-85121-159-5.

Le sujet n'est pas neuf, mais il est d'une richesse inépuisable, et la perspective ici adoptée, celle de la rhétorique religieuse, contribue à en renouveler l'étude. Dans leur avant-propos, les deux éditeurs indiquent clairement les buts assignés au colloque, - l'enquête se veut "fondée sur les textes et conduite au plus près des textes ", - et ils en synthétisent les apports. La plupart des 18 communications présentées sont centrées sur l'évocation d'un personnage singulier, historique ou mythique, dont on s'applique, le cas échéant, à faire voir les vicissitudes qu'a connues son exemplarité; d'Aristide le Juste à saint Séverin du Norique, au temps des invasions barbares, défilent successivement héros grecs et romains, saints et saintes chrétiennes, avec une section intermédiaire où sont examinés plusieurs cas intéressants de contamination des deux modèles; trois contributions examinent certains traitements du thème à l'époque moderne. Dans une remarquable conférence d'ouverture : "Le héros et le saint», J.-Cl. Fredouille esquisse la problématique du sujet, s'attachant à montrer les variations que subissent les modèles au gré des évolutions historiques, les continuités possibles entre les figures du héros et du saint, mais aussi leur irréductibilité, due essentiellement au caractère théocentrique de la conception chrétienne de la destinée. Trois index soignés (auteurs anciens cités, noms de personnes et de lieu) facilitent la consultation de l'ouvrage.

Cet intéressant colloque inaugurait les activités du C.A.R.R.A., lequel annonce aussi, pour bientôt, la publication d'une bibliographie relative à la prière dans l'Antiquité.

André Motte

(Université de Liège)

Raffaelle Pettazzoni, I Misteri. Saggio di una teoria storico religiosa, Presentazione di Dario Sabbatucci, Cosenza, L. Giordano Editore, 1997. 1 vol. $15 \times 21,5 \mathrm{~cm}, 245$ p. (Biblioteca di Studi Religiosi). ISBN : 88-86919-05-0.

Seventy-five years after the first publication, this welcome re-issue provides an opportunity to assess an important text of the history of religions: I Misteri by Raffaele Pettazzoni, the indisputable father of Italian historico-religious studies and founder of a school which numbers among its most prestigious exponents 